\title{
On the ductility of alpha titanium: The effect of temperature and deformation mode
}

DOI:

10.1016/j.actamat.2018.02.022

\section{Document Version}

Accepted author manuscript

Link to publication record in Manchester Research Explorer

\section{Citation for published version (APA):}

Orozco-Caballero, A., Li, F., Esque-De Los Ojos, D., Atkinson, M., \& Quinta da Fonseca, J. (2018). On the ductility of alpha titanium: The effect of temperature and deformation mode. Acta Materialia.

https://doi.org/10.1016/j.actamat.2018.02.022

\section{Published in:}

Acta Materialia

\section{Citing this paper}

Please note that where the full-text provided on Manchester Research Explorer is the Author Accepted Manuscript or Proof version this may differ from the final Published version. If citing, it is advised that you check and use the publisher's definitive version.

\section{General rights}

Copyright and moral rights for the publications made accessible in the Research Explorer are retained by the authors and/or other copyright owners and it is a condition of accessing publications that users recognise and abide by the legal requirements associated with these rights.

\section{Takedown policy}

If you believe that this document breaches copyright please refer to the University of Manchester's Takedown Procedures [http://man.ac.uk/04Y6Bo] or contact uml.scholarlycommunications@manchester.ac.uk providing relevant details, so we can investigate your claim.

\section{OPEN ACCESS}




\section{Accepted Manuscript}

On the ductility of alpha titanium: The effect of temperature and deformation mode

Alberto Orozco-Caballero, Feng Li, Daniel Esqué-de los Ojos, Michael D. Atkinson, João Quinta da Fonseca

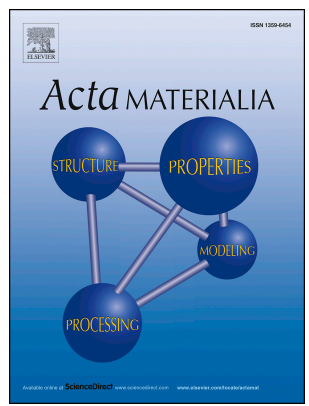

PII:

S1359-6454(18)30123-X

DOI:

10.1016/j.actamat.2018.02.022

Reference: $\quad$ AM 14378

To appear in: Acta Materialia

Received Date: 22 November 2017

Revised Date: 7 February 2018

Accepted Date: 9 February 2018

Please cite this article as: A. Orozco-Caballero, F. Li, D. Esqué-de los Ojos, M.D. Atkinson, J. Quinta da Fonseca, On the ductility of alpha titanium: The effect of temperature and deformation mode, Acta Materialia (2018), doi: 10.1016/j.actamat.2018.02.022.

This is a PDF file of an unedited manuscript that has been accepted for publication. As a service to our customers we are providing this early version of the manuscript. The manuscript will undergo copyediting, typesetting, and review of the resulting proof before it is published in its final form. Please note that during the production process errors may be discovered which could affect the content, and all legal disclaimers that apply to the journal pertain. 

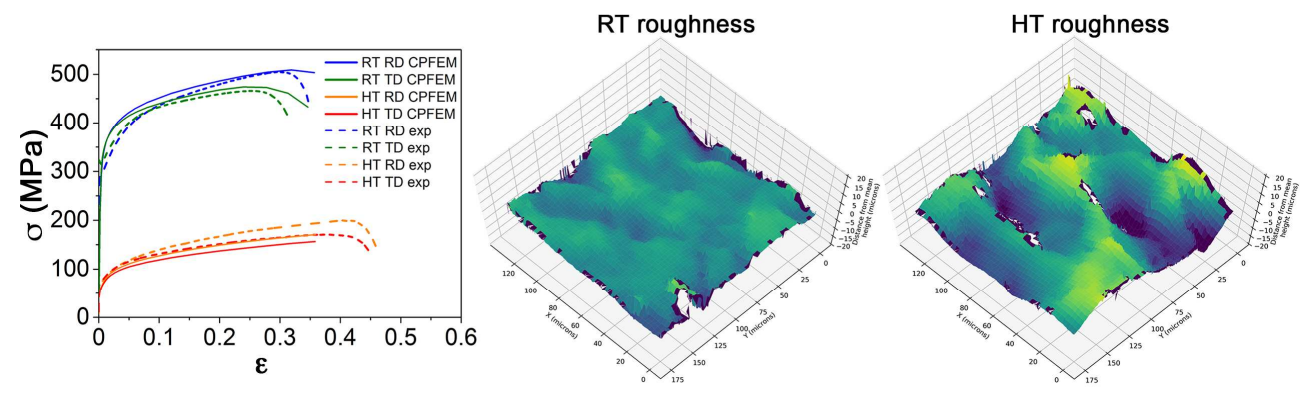


\section{On the ductility of alpha titanium: The effect of temperature}

\section{and deformation mode}

Alberto Orozco-Caballero ${ }^{\left(\mathrm{a},{ }^{*}\right)}$, Feng Li ${ }^{(\mathrm{a})}$, Daniel Esqué-de los Ojos ${ }^{(\mathrm{a}, \mathrm{b})}$, Michael D. Atkinson ${ }^{(a)}$, João Quinta da Fonseca ${ }^{\text {(a) }}$

(a) The University of Manchester, School of Materials, MSS Tower, Manchester, M13 9PL, United Kingdom.

(b) Institute of New Materials, College of Materials Science and Engineering, NanjingTech University, 210009, Nanjing, China

* Corresponding author: School of Materials, The University of Manchester, MSS Tower, M13 9PL, Manchester, United Kingdom. Email:

aorozcocaballero@gmail.com,alberto.orozco-caballero@manchester.ac.uk

\section{Abstract}

Single phase $\alpha$-titanium shows anomalous warm deformation behaviour. As the temperature increases, ductility increases in uniaxial tension and decreases in biaxial stretching. Previously, this behaviour was attributed to an increase in strain rate sensitivity and a decrease in twinning activity with temperature. In this study, we show that it can instead be explained by an increase in slip anisotropy with temperature. Grade $2 \mathrm{CP}$-Ti sheet was tested in uniaxial tension at $20^{\circ} \mathrm{C}$ and $300{ }^{\circ} \mathrm{C}$ to determine ductility, work hardening behaviour and the coefficient of plastic anisotropy (R-value). The increase in uniaxial ductility with temperature was found to be a consequence of an increasing rate of saturation work hardening with temperature. 
In the absence of significant twinning, this unexpected work hardening behaviour was attributed to an increase in slip anisotropy with temperature. This hypothesis was supported by crystal plasticity finite element modelling results, which are also able to predict the observed increase in surface roughness with temperature. The increase in anisotropy leads to higher strain localization which, coupled with the increasing work hardening rate helps explain why biaxial ductility decreases with increasing temperature. In addition to explaining the limitations in warm forming of $\mathrm{Ti}$, understanding the origins of these effects contributes to our general understanding of the deformation of other hexagonal metals like $\mathrm{Zr}$ and $\mathrm{Mg}$.

Keywords: Titanium; work hardening; anisotropy; formability; crystal plasticity finite element modelling

\section{1.- Introduction}

Despite its hexagonal crystal structure and consequent lack of easy slip systems, $\alpha$-titanium has excellent ductility and formability at room temperature [1-5]. Nevertheless, commercial purity titanium (CP-Ti) is not usually cold formed, primarily because of the strong rate of work hardening, which contributes to the setting up of high residual stress and high levels of spring-back. The amount of spring-back could potentially be reduced significantly via warm forming. In CP-Ti the main source of strengthening is interstitial solid solution strengthening, primarily by oxygen, and therefore its flow stress depends strongly on temperature: the flow stress of CP-Ti grade 2 (containing max. $0.25 \mathrm{wt}$ \% of oxygen) is some 3 times lower at $300{ }^{\circ} \mathrm{C}$ than at room temperature. Although this lower flow stress produces much less spring-back, CP-Ti sheet is usually formed above $500{ }^{\circ} \mathrm{C}$, near the recrystallization 
temperature [6]. This need for hot, rather than warm forming, arises in part because titanium has poor biaxial ductility and bendability when formed warm $[7,8]$.

However, this decrease in formability with increasing temperature is only manifested during biaxial stretching. In uniaxial tension, the ductility increases with increasing temperature, as expected $[1,9]$.

This apparently contradictory behaviour is not well known and has not been studied in detail, possibly because the forming of CP-Ti sheet is currently of only limited technological importance. However this behaviour is reported and discussed in Ti conference articles from the 1980's, primarily by Itoh et al [7] and Roberts and Wilson [8], where the increase in ductility in uniaxial tension with increasing temperature is attributed to an increase in strain rate sensitivity, whereas the decrease in biaxial ductility with increasing temperature is attributed to "a decrease in through thickness ductility" caused by increased surface roughness with increasing temperature. However, these explanations fail to explain why the ductility of $\mathrm{Ti}$ depends on the deformation mode, since the strain rate sensitivity in CP-Ti is dominated by dislocation solute interactions $[10,11]$, which should be unaffected by the change in deformation mode and the associated change in slip activity. Furthermore, the increase in surface roughness with temperature is seen after both uniaxial and biaxial stretching. Why does it only affect ductility in the biaxial case?

In this article, we report the results of a detailed study on the effect of temperature and loading mode on the ductility of grade $2 \mathrm{CP}-\mathrm{Ti}$. The aim was to understand the origin of this anomalous behaviour. We tested the material in uniaxial and biaxial tension, reproducing the anomalous behaviour reported previously and used electron-backscatter diffraction to characterise the material and measure the texture changes caused by deformation. The results of these tests revealed that the 
increase in ductility in uniaxial tension with temperature is due to a difference in work hardening behaviour that is unrelated to twinning. We used crystal plasticity finite element modelling to show that this work hardening behaviour could be caused by an increase in single crystal plastic anisotropy with temperature, which also leads to the observed increase in surface roughness.

\section{2.- Experimental procedure}

\section{1- Material}

The material studied is grade 2 commercially pure titanium $(\mathrm{CP}-\mathrm{Ti})(\leq 0.07 \mathrm{wt}$. $\% \mathrm{Fe}, \leq 0.08$ wt. $\% \mathrm{C}, \leq 0.03$ wt. $\% \mathrm{~N}, \leq 0.25$ wt. $\% \mathrm{O}, \leq 60$ ppm H, bal. Ti) in the form of $1 \mathrm{~mm}$ thickness rolled sheet.

\section{2- Microstructural characterization}

We used EBSD (Electron Backscattered Diffraction) to characterize the microstructure with a FEI Sirion equipped with an Oxford Instruments EBSD camera operating at an acceleration voltage of $20 \mathrm{kV}$ and using a step size of $0.25 \mu \mathrm{m}$. Samples were ground to \#4000 grit paper and finished with OP-S $(0.2 \mu \mathrm{m})$ suspension for $\sim 30$ min. EBSD data was analysed using the commercial Channel 5 software (Oxford Instruments). The contour pole figures were plotted using $10^{\circ}$ data clustering. In the EBSD maps after deformation, the twinned region was identified by first highlighting the twin boundaries in Channel 5 and then filling in the area contained by these twin boundaries. The twinned area fraction was subsequently obtained using the image analysis software ImageJ [12] by measuring the area fraction.

\section{3- Mechanical characterization}


Dog-bone tensile samples with $60 \times 12.5 \times 1 \mathrm{~mm}$ gauge dimensions were electro-discharge machined along the rolling direction (RD) and the traverse direction (TD). The samples were tested in a Instron 5589 universal testing machine equipped with a furnace at $\dot{\varepsilon}=10^{-4} \mathrm{~s}^{-1}$ and at room temperature (RT) and $300^{\circ} \mathrm{C}$. The strain was measured using a clip-on extensometer (gauge length of $50 \mathrm{~mm}$ ) and using digital image correlation (DIC). DIC was used primarily for measuring the strains along the width but also give strain along the length. Measurements of longitudinal strain using the extensometer showed excellent agreement with those from DIC and either could have been used. However, because the DIC measurements show more scatter at small strains, the extensometer values were preferred in the production of the stress strain $(\sigma-\mathcal{E})$ curves. Besides the true stress-strain curves obtained from the tensile tests, the work hardening $(\Theta)$ behaviour was studied by plotting the relationship $\Theta=\partial \sigma / \partial \varepsilon$ versus the true strain $(\varepsilon)$ for each testing condition. We also evaluated the strain rate sensitivity $(m)$ using Eq. 1 for different tensile tests at different strain rates in the range $\dot{\varepsilon}=10^{-4}-10^{-2} \mathrm{~s}^{-1}$.

$$
m=\left.\frac{\partial \log \sigma}{\partial \log \dot{\varepsilon}}\right|_{\varepsilon}
$$

To assess the change in formability during biaxial deformation, a set of Erichsen tests was carried out using a heated blank and punch at RT, $100^{\circ} \mathrm{C}$ and $300^{\circ} \mathrm{C}$ in an Erichsen 145 testing machine at a punch speed of $60 \mathrm{~mm} / \mathrm{min}$, using discs $13 \mathrm{~mm}$ in diameter and $1 \mathrm{~mm}$ thick. This punch speed produces strain rates in the biaxial stretch test to those used during uniaxial testing. Finally, we measured the surface roughness after mechanical testing using a confocal Bruker Contour Elite $\mathrm{K}$ with profiler function over a $170 \times 130 \mu \mathrm{m}$ area. 


\section{4- Digital Image Correlation}

We used digital image correlation (DIC) to measure strain along the tensile sample's width $\left(\varepsilon_{\mathrm{w}}\right)$ and length $\left(\varepsilon_{l}\right)$ at $\mathrm{RT}$ and $300^{\circ} \mathrm{C}$. A pattern was applied onto the sample surface using Dupli-Color Aqua ${ }^{\circledR}$ high quality lackspray (white speckles), followed by Dupli-Color Acryl Deco Matt ${ }^{\circledR}$ (black speckles) which provide a good variation in contrast, needed to perform the DIC calculations. We used a LaVision Imager ProX 4 Megapixel ${ }^{\circledR}(2048 \times 2048$ pixel resolution) camera to track the displacement of the paint speckles. The camera consists of a 14-bit charged couple device chip which was Peltier cooled to $-15^{\circ} \mathrm{C}$ in order to reduce the background noise, using an image acquisition frequency of $10 \mathrm{~Hz}$. The recorded sets of images were processed using LaVision Davis 8.2 ® correlation software using a final interrogation window of $32 \times 32$ pixels with a $25 \%$ overlap. We used Numerical Python [13] routines and representations using Matplotlib [14] to analyse the DIC data.

The displacement map at each frame was differentiated using a using second order accurate central differences method as implemented in Numpy [13]. The DIC analysis produces full-field in-plane displacement maps $\mathrm{u}\left(\mathrm{x}_{1}, \mathrm{x}_{2}, 0\right)$ on the plane $\mathrm{x}_{1} \mathrm{x}_{2}$ with normal $\mathrm{x}_{3}$. The instant total strains along the direction $i$ are calculated as:

$$
\varepsilon_{i}=\ln \left(1+\frac{\partial u_{i}}{\partial x_{i}}\right)
$$

In this study, the directions $i$ are denoted as $w, t$ and $l$ and correspond to the sample width, thickness and length, respectively. We used the values of $\varepsilon_{w}$ and $\varepsilon_{l}$ to calculate the plastic strain ratio (R-ratio), a measure of the plastic anisotropy of a sheet metal. Assuming volume constancy, $\Delta V / V=\varepsilon_{\mathrm{l}}+\varepsilon_{\mathrm{w}}+\varepsilon_{\mathrm{t}}=0$, the R-ratio is defined as follows:

$$
\text { R-ratio }=\frac{\varepsilon_{\mathrm{w}}}{\varepsilon_{\mathrm{t}}}=\frac{\varepsilon_{\mathrm{w}}}{-\varepsilon_{l}-\varepsilon_{\mathrm{w}}}
$$


Therefore we can use the DIC measurements of $\varepsilon_{w}$ and $\varepsilon_{l}$ to calculate a total R-ratio which includes both elastic and plastic strains. This is different from the R-ratio calculated from the final shape or plastic strain alone.

\section{5- Crystal Plasticity Finite Element Modelling}

The effect of the critical resolved shear stresses (CRSS) variations when testing at the two studied temperatures was simulated using three-dimensional crystal plasticity finite element modelling (CPFEM). The model consisted in a mesh of $15 \times 15 \times 1520$ node quadratic brick-shaped elements containing 8 integration points (IPs) per element. Orientations were given per element; hence each of the 8 IPs of an element had the same orientation, giving a total of 3375 grains. In the case of the modelling of

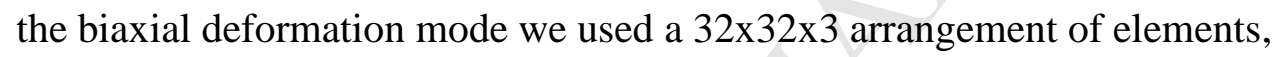
representing 3072 grains distributed in a sheet with three grains across the thickness.

A rate sensitive formulation was used in which plastic deformation is assumed to occur via slip according to:

$$
\frac{\dot{\gamma}^{\alpha}}{\dot{\gamma}_{\mathrm{o}}}=\left(\frac{\tau^{\alpha}}{\tau_{C R S S}^{\alpha}}\right)^{\frac{1}{m}}
$$

where $\dot{\gamma}^{\alpha}$ is the shear strain rate in the $\alpha$ slip system, $\dot{\gamma}_{o}$ is a nominal reference slip rate, $\tau^{\alpha}$ is the resolved shear stress in the $\alpha$ slip system, $\tau_{C R S S}^{\alpha}$ is the critical resolved shear stress in the $\alpha$ slip system and $m$ is the rate sensitivity $(m=0.02)$. The evolution of the CRSS values is governed by

$$
\Delta \tau_{C R S S}^{\alpha}=\sum_{\beta=1}^{n} H_{\alpha \beta}\left|\Delta \gamma^{\beta}\right|
$$

where $\Delta \gamma^{\beta}$ is the shear strain increment and $H_{\alpha \beta}$ is the hardening matrix between two slip systems $\alpha$ and $\beta$ : 


$$
H_{\alpha \beta}=L_{\alpha \beta} \Theta^{\alpha} ; \quad L_{\alpha \beta}=\left(\begin{array}{ccc}
1 & \cdots & 1 \\
\vdots & \ddots & \vdots \\
1 & \cdots & 1
\end{array}\right)
$$

$L_{\alpha \beta}$ is a matrix of $1 \mathrm{~s}$, indicating that all the slip systems interact between each other with the same strength. Finally, the hardening rate for the $\alpha$ slip system, $\Theta^{\alpha}$, can be expressed using the Voce hardening equation:

$$
\Theta^{\alpha}=\Theta_{\mathrm{IV}}+\Theta_{\mathrm{I}}\left(1-\frac{\tau^{\alpha}}{\tau_{\mathrm{s}}}\right)^{a}
$$

where $\Theta_{\mathrm{IV}}$ is the work hardening rate in the stage IV, $\Theta_{\mathrm{I}}$ is the initial work hardening rate at $\sigma=0, \tau_{\mathrm{S}}$ is the saturation shear stress and $a$ controls the rate of change in hardening with shear stress. In this case we considered 4 slip families, namely: (a) basal, (b) prismatic $<\mathrm{a}>$, (c) pyramidal $<\mathrm{a}>$ and (d) pyramidal $<\mathrm{c}+\mathrm{a}>$. In the present model, we intentionally selected the hardening parameters to fit just the initial curvature in the tensile curves, at low strain values. The initial slip resistances and hardening parameters are listed later in the discussion of the modelling results. A detailed description on the solution algorithm used can be found in [15].

\section{3.- Results}

\section{1- Microstructural characterization}

The EBSD map in the RD-TD plane and pole figures of the as-received material are showed in Fig. 1. The microstructure is made up of equiaxed grains with an average size of about $20 \mu \mathrm{m}$. However, there is some variation of grain size in the material, with some regions containing grains up to $100 \mu \mathrm{m}$ in diameter. The $\{0001\}$ pole figure presents a predominance of basal planes parallel to the RD-TD plane but split around ND towards TD. This is a typical texture for this material in the rolled and recrystallized condition which produces mechanical anisotropy. 
Fig. 2a and $\mathrm{b}$ show EBSD maps on the RD-ND plane for samples after tensile testing to an elongation of $15 \%$ at $\dot{\varepsilon}=10^{-4} \mathrm{~s}^{-1}$ at $\mathrm{RT}$ and $300{ }^{\circ} \mathrm{C}$, respectively. Although there is a noticeable difference in the grain size of the grains in the two maps, this is simply a result of variability in the starting material and not a consequence of dynamic recrystallization or grain growth. $\mathrm{CP}-\mathrm{Ti}$ does not recrystallize at $300{ }^{\circ} \mathrm{C}$, as the grain misorientation evident in the EBSD map confirms.

The maps show orientation gradients within each grain which is evidence of substructure formation. Additionally, Fig. 2c and d highlight the twins extracted from each map in Fig. 2a and b at RT and $300{ }^{\circ} \mathrm{C}$, respectively. The twined material volume fraction is around $2.5 \%$ at RT and $1 \%$ at $300{ }^{\circ} \mathrm{C}$, and is made up of both compression $\{11 \overline{2} 2\}\langle 11 \overline{2} \overline{3}\rangle$ and tension $\{10 \overline{1} 2\}\langle 10 \overline{1} \overline{1}\rangle$ twins at RT while only a few tension $\{10 \overline{1} 2\}\langle 10 \overline{1} \overline{1}\rangle$ twins are observed at $300^{\circ} \mathrm{C}$. Finally, Fig. 2e and f present the pole figures obtained from the maps in Fig. 2a and b, respectively. As expected, the microtexture after deformation remains essentially similar to the as-received material.

\section{2- Mechanical characterization}

The true $\sigma-\varepsilon$ tensile curves at a strain rate of $10^{-4} \mathrm{~s}^{-1}$ are shown in Fig. 3a, for the two testing directions RD and TD, at RT and $300{ }^{\circ} \mathrm{C}$. The material has a noticeable upper yield point, which has been attributed to interstitial oxygen [1]. The yield stress $\left(\sigma_{0.2}\right)$ and the maximum flow stress $\left(\sigma_{\max }\right)$ decrease sharply with the modest increase in testing temperature for both testing directions. For instance, the $\sigma_{0.2}$ values at $\mathrm{RT}$ are $288 \mathrm{MPa}$ for $\mathrm{RD}$ and $316 \mathrm{MPa}$ for TD whereas at $300{ }^{\circ} \mathrm{C}$ values are $72 \mathrm{MPa}$ and $74 \mathrm{MPa}$ respectively. The $\sigma_{\max }$ values at RT are $504 \mathrm{MPa}$ for RD and $465 \mathrm{MPa}$ for TD and $200 \mathrm{MPa}$ and $170 \mathrm{MPa}$ at $300{ }^{\circ} \mathrm{C}$ respectively. The ductility increases with increasing testing temperature for both testing directions. The values of 
elongation to failure, $e_{\mathrm{F}}$ are $43 \%$ for $\mathrm{RD}$ and $38 \%$ for TD at RT while at $300{ }^{\circ} \mathrm{C}$ it reaches values of 59 and $57 \%$ for RD and TD respectively. Comparing the mechanical behaviour between the two testing directions, in general, the values of $\sigma_{0.2}$ when testing along RD are lower than TD. Nevertheless, RD has higher values of $\sigma_{\max }$. Additionally, the ductility is higher when testing along RD than TD. This difference in behaviour with testing direction is probably a consequence of the crystallographic texture of the rolled sheet (Fig. 1).

The evolution of the work-hardening rate with strain is shown in Fig. 3b. At the onset of plastic deformation, the curves exhibit a hump followed by a smooth decrease. Previous work has attributed this behaviour to the occurrence of twinning after yielding, especially at room temperature [16-18]. However, there are only a few twins in the EBSD maps in Fig. 2, suggesting that there is only a very limited amount of twinning, in accordance with other more recent work [1]. Instead this brief work hardening rate increase at low deformation values is likely to be related to the upper yield point observed, which is probably caused by interstitial oxygen [1,9]. As expected, the work hardening at low strains is higher at RT than at $300{ }^{\circ} \mathrm{C}$. At RT, the work hardening rate starts to drop just after a strain of 0.17 and 0.26 for the TD and $\mathrm{RD}$ directions respectively, which does not happen at $300^{\circ} \mathrm{C}$ until the strain reaches around 0.35 . The necking onset obtained from the Considere's criteria is highlighted with a black dot in both, the true $\sigma-\varepsilon$ tensile curves and the work-hardening rate curves.

A consequence of this unusual hardening behaviour is that the uniform elongation, $\varepsilon_{\mathrm{u}}$, is higher at $300{ }^{\circ} \mathrm{C}$ than at RT. At the same time, the elongation after necking $\left(\Delta \varepsilon_{\mathrm{p}}\right)$ is only slightly higher at $300{ }^{\circ} \mathrm{C}$ than at RT (Fig. 4 ), which suggests there is only a small increase in strain rate sensitivity with increasing temperature. 
This implies that the increase in ductility with increasing temperature is almost entirely due to an increase in $\varepsilon_{\mathrm{u}}$, represented by $\Delta \varepsilon_{\mathrm{T}}$ in Fig. 4. This observation is consistent with the strain rate sensitivity $(m)$ values measured at different strain rates $\left(10^{-4}-10^{-2} \mathrm{~s}^{-1}\right)$, which for both testing directions are around 0.03 at RT and 0.04 at 300 ${ }^{\circ} \mathrm{C}$, in agreement with other measurements [19]. The strain rate sensitivity changes gradually with temperature and strain, suggesting the same deformation mechanisms are operative in the temperature and strain regimes tested.

To assess the plastic anisotropy of the material at different temperatures, the Rratio was calculated from DIC strain data obtained during the test (Fig. 3c). An Rratio higher than one indicates that, during plastic deformation, $\varepsilon_{\mathrm{t}}$ the strain in the thickness direction (ND) is lower than the strain along the width $\varepsilon_{\mathrm{w}}(\mathrm{RD}, \mathrm{TD})$. Given the starting texture of the material, with alignment of the 0002 poles around ND, an R-ratio higher than one is expected. The measured R-ratio, shown in Fig 3c, lies between 3 and 4 for all tests after a strain of 0.05 where it is essentially constant. The highest value is for the tests along TD, for which it is temperature independent. When loading along $\mathrm{RD}$, the $\mathrm{R}$-ratio at $300^{\circ} \mathrm{C}$ is higher than that at $\mathrm{RT}$, suggesting anisotropy increases with temperature. There is a peak in R-ratio at yield in all tests, which is higher for TD loading and which broadens with increasing temperature. However, its significance cannot be easily determined, since the R-ratio definition used here contain elastic strain contributions.

The biaxial stretching tests confirmed the previous finding $[7,8]$ that, unlike in uniaxial tension, ductility during biaxial deformation decreases with increasing temperature. Fig. 5 shows the drawing force $(F)$ vs. punch stroke $(d)$ curves at three testing temperatures. The curves reveal that, as expected from the tensile test results, 
the required force for deforming the material is lower at higher testing temperatures than at room temperature. However, whereas in tension the ductility increased with temperature, here the maximum punch stroke decreases. More precisely, the maximum dome height at $300{ }^{\circ} \mathrm{C}$ is two-thirds of that at room temperature.

\section{4.- Discussion}

The mechanical testing results confirm that CP-Ti behaves atypically in the temperature range studied. There is an anomalous increase in saturation work hardening and anisotropy with increasing temperature in uniaxial tests and whereas the ductility decreases with increasing temperature in biaxial stretching, it increases in uniaxial stretching.

\section{1- Anomalous higher work hardening behaviour at high testing temperature}

The main source of strain hardening is usually assumed to be the interaction between dislocations [20-23]. Therefore, strain hardening should decrease with increasing temperature, since recovery will happen more readily at high temperatures $[24,25]$. Therefore, it is unsurprising that the initial work hardening rate is higher at RT than at $300^{\circ} \mathrm{C}$. However, with increasing plastic strain, the work hardening rate at RT saturates and drops just before necking occurs. At $300^{\circ} \mathrm{C}$, on the other hand, this drop with strain is much more gradual suggesting a different source of work hardening exists at this temperature. This is an important observation since it is this higher hardening rate, which coupled with the lower flow stress, delays necking and increases ductility.

Our EBSD observations exclude twinning as a possible source of this enhanced hardening and support the idea that there should be less twinning at higher 
temperatures $[1,26]$. If twin activity is negligible, then the increased plastic anisotropy, as measured by the R-ratio, must be due to changes in relative slip activity.

Although the slip resistance of hard slip modes like $\langle c+a\rangle$ slip decreases with increasing temperature, this is true for all slip systems. However, making hard slip systems easier does not necessarily decrease slip anisotropy. The anisotropy is not determined by the $\langle c+a\rangle$ slip resistance but instead by the ratio of $\langle a\rangle$ and $<c+a>$ slip resistance. If the thermal component of the slip resistance is an additional term and similar in magnitude for both slip systems, then increasing temperature can increase the ratio of slip resistances, even if both decrease.

This idea is consistent with the variation of measured critical resolved shear stress (CRSS) values for $\langle a\rangle$ and $\langle c+a\rangle$ with temperature reported in Lutjering and Williams for Ti-6.6Al alloy [26]. Although the slip resistance decreases for all slip systems, the $\operatorname{CRSS}(<c+a>) / \operatorname{CRSS}(<a>)$ ratio actually increases with increasing temperature [27]. CP-Ti can be even more anisotropic than its alloys [5,28] and therefore, this effect is possibly even more pronounced than in the Al containing alloy.

The consequence of this increasing slip anisotropy, is that the grains poorly aligned for easy slip become even harder to deform with increasing temperature, effectively behaving as a hard second phase, at least along certain directions. The presence of these hard grains could contribute to hardening via the generation of back-stress caused by the incompatibility in deformation between them and other better aligned, softer grains. This hardening mechanism was originally studied by Ashby [29], Brown and Stobbs [30] and Mory and Tanaka [31] in particle reinforced aluminium, where the hard phase is undeformable. It is not clear, therefore, whether 
these back-stress arguments apply to CP-Ti with high single crystal plastic anisotropy. High plastic anisotropy can have pronounced effects of the early work hardening of magnesium, which can be reproduced by elasto-plastic self-consistent (EPSC) modelling [32]. However, its significance at larger strains is more difficult to assess since the predictions of EPSC models are restricted to small deformations.

Nevertheless, it offers a possible explanation for the anomalous behaviour observed. To test this hypothesis, we performed a series of simulations using crystal plasticity finite element modelling (CPFEM), which should be able to reproduce the effects of increasing anisotropy on work hardening.

We used a temperature independent formulation and simulated the mechanical behaviour of CP-Ti at the two temperatures by varying the $\mathrm{CRSS}(<c+$ $a>) / \mathrm{CRSS}(<a>)$ ratios, as shown in Table 1, which also includes the compliance values, the initial CRSS values for each slip family as well as the hardening parameters at room temperature and $300^{\circ} \mathrm{C}$ for the prismatic slip family. Although the elastic compliance changes with temperature, this effect is small between RT and 300 ${ }^{\circ} \mathrm{C}$ and was ignored, as was twinning, the extent of which EBSD showed to be minimal. The texture measured using EBSD and shown in Fig. 1 was used to produce discrete representative orientations to be used in the CPFE simulations, which corresponds to the pole figures presented in Fig. 6 a.

The main aim of the simulations was to explore the effect of changing anisotropy on the saturation work hardening rate. However, the initial hardening is also different at the two temperatures, since recovery occurs more readily at $300{ }^{\circ} \mathrm{C}$ than at room temperature. To account for this effect, the parameters of a Voce-type hardening law were determined by fitting the initial portion of the stress strain curves. 
To keep the number of parameters to a minimum, work hardening was assumed to act only in the prismatic slip system. The resultant change in work hardening for prismatic slip calculated using Eq. 7 is shown in Fig. 7. The figure shows how the hardening parameters in Table 1 only determine the initial work hardening rate and that this contribution to hardening disappears well before necking starts. Assuming the applied stress, $\sigma$, is related to the resolved shear stress $\tau$ by $\sigma=2 \tau$, the Voce hardening contribution of Eq. 7 in the overall hardening finish at $\sigma=80 \mathrm{MPa}$ and $\sigma=320 \mathrm{MPa}$ for the $300{ }^{\circ} \mathrm{C}$ and $\mathrm{RT}$ simulations respectively. This is well below necking in both cases, as Fig. 3a shows.

The experimental and simulated uniaxial true stress - strain curves are compared in in Fig. 8a. The curves show that a reasonable calibration is possible using a simple hardening model for prismatic slip only. As expected, the simulated stress-strain curves do not show an upper yield point, since there is no mechanism for it in the crystal plasticity model. Apart from that, however, the predicted work hardening responses, shown in Fig. 8b, capture all the main features of the experimental work hardening curves. In particular, the model reproduces the increase in saturation work hardening rate with increasing anisotropy at $300{ }^{\circ} \mathrm{C}$, as well as the increased uniform elongation it enables. There is also good agreement between the CPFEM simulated R-ratio values, shown in in Fig. 8c, and those determined experimentally (Fig. 3c), further supporting the idea that the plastic anisotropy increases as the temperature increases from $300^{\circ} \mathrm{C}$ to $\mathrm{RT}$.

Additionally, the simulated microtexture after $15 \%$ deformation at RT and $300{ }^{\circ} \mathrm{C}$ are presented in Fig. $6 \mathrm{~b}$ and c, respectively. They both present good agreement 
with the pole figures observed for the experimental results in Fig 2e-f, supporting the model formulation.

These CPFEM results demonstrate that increasing slip anisotropy can indeed contribute to work hardening. Although it is possible that this effect is a consequence of geometric hardening caused by texture evolution, a comparison between the predictions of a visco-plastic self-consistent model (VPSC) and CPFEM [33] has shown that the effect of texture evolution is very weak and actually produces softening in uniaxial tension. The same study also showed that the effect of anisotropy on hardening is only predicted by the CPFEM and not by the VPSC model, implying that it probably arises from the elastic interactions between grains and the resultant back-stresses, which are not accounted for in the viscoplastic self-consistent formulation. Although this effect is most noticeable at higher temperatures, anisotropy induced back-stresses must contribute to work hardening at all temperatures, including RT. Therefore, in hexagonal materials, the work hardening rate is determined by both back-stresses and dislocation hardening. The evidence here is that, in $\mathrm{CP}-\mathrm{Ti}$, the dislocation density contribution saturates very early and that the back-stress term dominates as the material approaches necking. This large contribution of back-tresses to work hardening could help explain why spring-back in CP-Ti is so pronounced and notoriously difficult to model.

At higher temperatures, the plastic anisotropy increases but the slip resistance decreases. The consequence is a delay in the onset of necking by Considére's criterion and therefore increased ductility. Although hexagonal materials are often said to be brittle because of their high plastic anisotropy, a consequence of the limited availability of slip systems, here CP-Ti becomes more ductile with increasing 
temperature because of increasing anisotropy and its effect on work hardening. The effect on biaxial ductility, however, is the opposite.

\section{2- Decreasing ductility in biaxial conditions at high testing temperature}

Although increasing the temperature improves uniaxial ductility, it decreases biaxial ductility. Our results are consistent with those of Itoh et al. [7] who showed that the bendability of CP-Ti decreases at $300{ }^{\circ} \mathrm{C}$ before increases again at around 500 ${ }^{\circ} \mathrm{C}$, closer to the usual forming temperature for CP-Ti [26]. In their study, they also observed that by weakening the texture, i.e. decreasing the R-ratio, the formability at $300{ }^{\circ} \mathrm{C}$ can be improved. Similar results were obtained by Roberts and Wilson [8], who found that formability deteriorates from room temperature to $200{ }^{\circ} \mathrm{C}$ before improving again up to $500{ }^{\circ} \mathrm{C}$. They also showed that decreasing formability when increasing testing temperature was correlated to an increase in the surface roughness, and that the rate at which surface roughening develops during stretching is proportional to grain size.

Roberts and Wilson attributed the increase in surface roughening at higher temperatures to the loss of twinning as an operative deformation mechanism, although they presented limited evidence for it in the form of optical micrographs (EBSD had not yet been developed). Their argument was that twinning effectively reduces the effective grain size during deformation, reducing surface roughness [8]. However, we found only limited amounts of twinning in the material after stretching and then mostly near the tool and not in the bulk. This is consistent with the texture of the material and the anisotropic nature of twinning. However, one would expect for surface roughness to increase with increasing slip anisotropy - even in the absence of twinning. 
Our measurements of surface roughness, summarised in Table 2 and illustrated in the case of the biaxial stretching after fracture at RT and $300{ }^{\circ} \mathrm{C}$ in Fig. 9, confirm Roberts and Wilson's correlation between decreasing biaxial ductility with increasing surface roughness with increasing temperature. In order to see if this could be a consequence of the increasing single crystal slip anisotropy, the same CPFEM model used to simulate uniaxial deformation was used to simulate biaxial stretching and the accompanying surface roughening. The results of these simulations are shown in Fig 10. The model predicts that the surface roughness increases with temperature, in agreement with the measurements. This shows that the increasing roughness can be explained by the higher $\operatorname{CRSS}(<c+a>) / \operatorname{CRSS}(<a>)$ ratio at high temperatures alone and that twinning is not required to explain it. The overestimation of surface roughness in the simulation is probably a direct consequence of using only 3 grains across the thickness of the modelled volume due to computational cost, when the sheet tested contains approximately 50 grains across the thickness. The fewer the grains across the thickness, the bigger the effect of the slip anisotropy on the surface roughness. This is consistent with the correlation between starting grain size and surface roughness measured for different materials [8].

Like in the uniaxial simulations, where necking occurred when the Considére's criterion was met, the biaxial simulations also produce a strain localization events. Because in uniaxial testing the material is unconstrained in the transverse direction, the material can plastically deform without developing high triaxial stresses until necking occurs. In biaxial stretching however, the material deformation is much more constrained, which in turn enhances the effect of strain localization on failure by promoting the early development of triaxial stresses and 
damage. Therefore, whereas in uniaxial tension the increasing slip anisotropy with temperature promotes ductility by increasing the work hardening rate, in biaxial stretching it leads to enhanced strain localisation and stress triaxiality leading to earlier failure. In other words, in tension the incompatibility between soft and hard grains increases ductility, in biaxial stretching it decreases it.

\section{5.- Conclusions}

The effect of temperature on the ductility of CP-Ti deformed warm (below the recrystallization temperature) depends on the deformation mode. Whereas increasing the temperature improves ductility in uniaxial tension it decreases it in biaxial stretching. Previously, these effects had been explained by higher strain rate sensitivity and lower twinning activity respectively. However, we have shown that they can be both explained by increasing slip anisotropy with temperature. The increasing anisotropy contributes to work hardening, extending uniform elongation in uniaxial tension and increasing ductility, whilst promoting strain localization and damage formation during biaxial stretching and decreasing ductility. The effect of plastic anisotropy on work hardening is often ignored but, as this work shows, it can have a significant effect on the behaviour of hexagonal materials. In addition to its effects on warm formability, it is probably very relevant to spring-back in these materials, which is notoriously difficult to predict.

\section{Acknowledgments}

The authors would like to thank the EPSRC for funding this study through the programme grant EP/H020047/1, Light Alloys for Sustainable Transport $2^{\text {nd }}$ Generation (LATEST2) and programme grant EP/R001715/1, LightForm. We would 
like to thank Prof. T. Mori for enlightening discussions on back-stresses and work hardening.

\section{References}

[1] S. Nemat-Nasser, W.G. Guo, J.Y. Cheng, Mechanical properties and deformation mechanisms of a commercially pure titanium, Acta Mater. 47 (1999) 3705-3720. doi:10.1016/S1359-6454(99)00203-7.

[2] I. Weiss, S.L. Semiatin, Thermomechanical processing of alpha titanium alloys_an overview, Mater. Sci. Eng. A. 263 (1999) 243-256. doi:10.1016/S09215093(98)01155-1.

[3] F.-K. Chen, K.-H. Chiu, Stamping formability of pure titanium sheets, J. Mater. Process. Technol. 170 (2005) 181-186. doi:10.1016/j.jmatprotec.2005.05.004.

[4] J. Adamus, Stamping of Titanium Sheets, Key Eng. Mater. 410-411 (2009) 279-288. doi:10.4028/www.scientific.net/KEM.410-411.279.

[5] M.E. Nixon, O. Cazacu, R.A. Lebensohn, Anisotropic response of high-purity $\alpha$-titanium: Experimental characterization and constitutive modeling, Int. J. Plast. 26 (2010) 516-532. doi:10.1016/j.ijplas.2009.08.007.

[6] F.M. Güçlü, H. Çimenoğlu, E.S. Kayalı, The recrystallization and thermal oxidation behavior of CP-titanium, Mater. Sci. Eng. C. 26 (2006) 1367-1372. doi:10.1016/j.msec.2005.08.012.

[7] N. Itoh, M. Ogaya, S. Ishiyamai, T. Matsushita, Y. Hayashi, M. Koike, J. Joetsu, The press formability of commercial pure titanium at warm working temperature, in: Titanium80 Sci. Technol. Proc. Fourth Int. Conf. Titan. Metall. Soc. AIME, Metallurgical Society of AIME, Kyoto, Japan, 1980: p. 2523.

[8] W.T. Roberts, D.V. Wilson, Warm Forming of Titanium Sheet, in: Titan. Sci. Technol., Deutsche Gesselschaft für Metallkunde, 1985: pp. 539-546.

[9] M. Doner, H. Conrad, Deformation mechanisms in commercial Ti (0.5 at. pct oineq) at intermediate and high temperatures (0.3 - 0.6 tinm), Metall. Trans. 4 (1973) 2809-2817. doi:10.1007/BF02644581.

[10] A.M. Garde, A.T. Santhanam, R.E. Reed-Hill, The significance of dynamic strain aging in titanium, Acta Metall. 20 (1972) 215-220. doi:10.1016/00016160(72)90183-6.

[11] C. Sévérac, B. Deslandes, A. Reyes, C. Quesne, P. Lacombe, Étude du comportement au fluage du titane de purete commerciale entre 25 et $400{ }^{\circ} \mathrm{C}$-rôle des impuretés et/ou des éléments d'alliage, J. Common Met. 69 (1980) 237-250. doi:10.1016/0022-5088(80)90057-0.

[12] C.A. Schneider, W.S. Rasband, K.W. Eliceiri, NIH Image to ImageJ: 25 years of image analysis, Nat. Methods. (2012). doi:10.1038/nmeth.2089.

[13] S. van der Walt, S.C. Colbert, G. Varoquaux, The NumPy Array: A Structure for Efficient Numerical Computation, Comput. Sci. Eng. 13 (2011) 22-30.

doi:10.1109/MCSE.2011.37.

[14] J.D. Hunter, Matplotlib: A 2D Graphics Environment, Comput. Sci. Eng. 9 (2007) 90-95. doi:10.1109/MCSE.2007.55.

[15] P. Bate, Modelling deformation microstructure with the crystal plasticity finite-element method, Philos. Trans. R. Soc. Lond. Math. Phys. Eng. Sci. 357 (1999) 1589-1601. doi:10.1098/rsta.1999.0391. 
[16] A.A. Salem, S.R. Kalidindi, R.D. Doherty, Strain hardening regimes and microstructure evolution during large strain compression of high purity titanium, Scr. Mater. 46 (2002) 419-423. doi:10.1016/S1359-6462(02)00005-2.

[17] A.A. Salem, S.R. Kalidindi, R.D. Doherty, Strain hardening of titanium: role of deformation twinning, Acta Mater. 51 (2003) 4225-4237. doi:10.1016/S13596454(03)00239-8.

[18] A.A. Salem, S.R. Kalidindi, S.L. Semiatin, Strain hardening due to deformation twinning in $\alpha$-titanium: Constitutive relations and crystal-plasticity modeling, Acta Mater. 53 (2005) 3495-3502. doi:10.1016/j.actamat.2005.04.014. [19] W.-S. Lee, C.-F. Lin, Plastic deformation and fracture behaviour of Ti-6Al4V alloy loaded with high strain rate under various temperatures, Mater. Sci. Eng. A. 241 (1998) 48-59. doi:10.1016/S0921-5093(97)00471-1.

[20] U.F. Kocks, Laws for Work-Hardening and Low-Temperature Creep, J. Eng. Mater. Technol. 98 (1976) 76-85. doi:10.1115/1.3443340.

[21] H. Gao, Y. Huang, W.D. Nix, J.W. Hutchinson, Mechanism-based strain gradient plasticity - I. Theory, J. Mech. Phys. Solids. 47 (1999) 1239-1263. doi:10.1016/S0022-5096(98)00103-3.

[22] H.M. Zbib, T. Díaz de la Rubia, M. Rhee, J. P. Hirth, 3D dislocation dynamics: stress-strain behavior and hardening mechanisms in fcc and bcc metals, J. Nucl. Mater. 276 (2000) 154-165. doi:10.1016/S0022-3115(99)00175-0.

[23] A. Seeger, J. Diehl, S. Mader, H. Rebstock, Work-hardening and worksoftening of face-centred cubic metal crystals, Philos. Mag. 2 (1957) 323-350. doi:10.1080/14786435708243823.

[24] A. Seeger, The temperature dependence of the critical shear stress and of work-hardening of metal crystals, Lond. Edinb. Dublin Philos. Mag. J. Sci. 45 (2016) 771-773. doi:10.1080/14786440708520489.

[25] J. Gil Sevillano, P. van Houtte, E. Aernoudt, Large strain work hardening and textures, Prog. Mater. Sci. 25 (1980) 69-134. doi:10.1016/0079-6425(80)90001-8.

[26] Fundamental Aspects, in: Titanium, Springer Berlin Heidelberg, 2007: pp. 1552. doi:10.1007/978-3-540-73036-1_2.

[27] M. Preuss, J.Q. da Fonseca, V. Allen, D.G.L. Prakash, M.R. Daymond, Twinning in structural material with a hexagonal close-packed crystal structure, J. Strain Anal. Eng. Des. 45 (2010) 377-390. doi:10.1243/03093247JSA624.

[28] M.J. Philippe, E. Bouzy, J.J. Fundenberger, Textures and anisotropy of titanium alloys, Mater. Sci. Forum. 273-275 (1988) 511-522.

[29] M.F. Ashby, Work hardening of dispersion-hardened crystals, Philos. Mag. 14 (1966) 1157-1178. doi:10.1080/14786436608224282.

[30] L.M. Brown, W.M. Stobbs, The work-hardening of copper-silica, Philos. Mag. 23 (1971) 1201-1233. doi:10.1080/14786437108217406.

[31] T. Mori, K. Tanaka, Average stress in matrix and average elastic energy of materials with misfitting inclusions, Acta Metall. 21 (1973) 571-574.

doi:10.1016/0001-6160(73)90064-3.

[32] S.R. Agnew, R.P. Mulay, F.J. Polesak III, C.A. Calhoun, J.J. Bhattacharyya, B. Clausen, In situ neutron diffraction and polycrystal plasticity modeling of a $\mathrm{Mg}-$ $\mathrm{Y}-\mathrm{Nd}-\mathrm{Zr}$ alloy: Effects of precipitation on individual deformation mechanisms, Acta Mater. 61 (2013) 3769-3780. doi:10.1016/j.actamat.2013.03.010.

[33] D. Esqué-de los Ojos, C.-T. Nguyen, A. Orozco-Caballero, G. Timár, J. Quinta da Fonseca, Back-stresses and geometrical hardening as competing mechanisms enhancing ductility in HCP metals, Submitt. Mater. Des. (2017). 


\section{Figure captions}

Fig. 1. EBSD map and pole figures obtained in the RD-TD plane for the as-received CP-Ti.

Fig. 2. EBSD map in the RD-ND plane after a macroscopic deformation of $15 \%$ at $\dot{\varepsilon}=10^{-4} \mathrm{~s}^{-1}$ and at a) RT and b) $300{ }^{\circ} \mathrm{C}$. The compression $\{11 \overline{2} 2\}\langle 11 \overline{2} \overline{3}\rangle$ and tension $\{10 \overline{1} 2\}\langle 10 \overline{1} \overline{1}\rangle$ twins are highlighted in blue and red, respectively, for the tested material at c) RT and d) $300{ }^{\circ} \mathrm{C}$. Pole figures at e) RT and f) $300{ }^{\circ} \mathrm{C}$ after deformation.

Fig. 3. a) True stress-true strain $(\sigma-\varepsilon)$ curves b) work hardening vs. true strain $(\Theta-\varepsilon)$ and c) R-ratio vs. true strain (R-ratio- $\varepsilon$ ) at $\dot{\varepsilon}=10^{-4} \mathrm{~s}^{-1}$ for the two temperatures along $\mathrm{RD}$ and TD. The necking onset obtained from the Considere's criteria are highlighted with a black dot for each condition.

Fig. 4. Values of uniform elongation $\left(\varepsilon_{\mathrm{u}}\right)$ and elongation to failure $\left(\varepsilon_{\mathrm{f}}\right)$ at $\dot{\varepsilon}=10^{-4} \mathrm{~s}^{-1}$ for the two temperatures along RD and TD obtained from the Considere's criteria. The difference $\varepsilon_{\mathrm{f}}-\varepsilon_{\mathrm{u}}$ is represented by $\Delta \varepsilon_{\mathrm{p}}$, which represents the post-uniform elongation while $\Delta \varepsilon_{\mathrm{T}}$ represent the increase in elongation attributed to the increasing temperature.

Fig. 5. Drawing force vs. punch stroke $(F-d)$ at three testing temperatures obtained from the Erichsen test.

Fig. 6. a) Initial texture used in the CPFE simulations. Pole figures obtained from the simulations after $15 \%$ deformation at b) RT and c) $300{ }^{\circ} \mathrm{C}$.

Fig. 7. Hardening $(\theta)$ as a function of the shear stress $(\tau)$ for prismatic slip at two temperatures.

Fig. 8. (a) Modelled (solid lines) and experimental (dashed lines) true stress-true strain $(\sigma-\varepsilon)$ curves (b) modelled work hardening vs. true strain $(\Theta-\varepsilon)$ and $(\mathbf{c})$ modelled R-ratio vs. true strain (R-ratio- $\varepsilon$ ) for the two simulated testing temperatures when testing along RD and TD.

Fig. 9. Experimental values of the distance from the mean height under biaxial testing conditions after fracture (a) at RT and (b) at $300{ }^{\circ} \mathrm{C}$. 
Fig. 10. Roughness CPFEM simulated for both equivalent temperatures: (a) Ra- $\varepsilon$ evolution and (b) values of the distance from the mean height in the surface at three different strain values. 
Table 1. Selected compliance values, initial $\tau_{\text {CRSS }}^{\alpha}$ and hardening parameters for the prismatic slip family used in the CFEM simulation.

\begin{tabular}{|c|c|c|c|c|}
\hline \multicolumn{5}{|c|}{ Compliance values $(\times$ 10-6 MPa) $[31]$} \\
\hline$S_{11}$ & $S_{33}$ & $S_{12}$ & $S_{13}$ & $S_{66}$ \\
\hline 9.62 & 8.01 & 29.94 & -2.46 & 28.58 \\
\hline \multicolumn{5}{|c|}{ Initial critical resolved shear stress values (MPa) } \\
\hline & Basal & Prism. $\langle a>$ & Pyram. $\langle\mathbf{a}\rangle$ & Pyram. $\langle\mathbf{c}+\mathbf{a}>$ \\
\hline RT [32] & 162.4 & 100.0 & 128.8 & 221.2 \\
\hline \multirow[t]{4}{*}{$300^{\circ} \mathrm{C}$} & 20.0 & 20.0 & 20.0 & 141.2 \\
\hline & & & & $+\sqrt{2-1}$ \\
\hline & Hardening & rameters for prisma & tic slip family & $\gamma$ \\
\hline & $\theta_{\mathrm{IV}}$ & $\theta_{\mathbf{I}}$ & $\tau_{\mathbf{s}}$ & $a$ \\
\hline RT & 0 & 105000 & 650 & 20 \\
\hline $300^{\circ} \mathrm{C}$ & 0 & 10000 & 210 & 18 \\
\hline
\end{tabular}

Table 2. Roughness values $(R a)$ measured after testing at different temperatures in uniaxial and biaxial conditions. The as-received material roughness was 0.8 .

\begin{tabular}{lccccc}
\hline \multirow{2}{*}{ Uniaxial test } & $\mathrm{T}\left({ }^{\circ} \mathrm{C}\right)$ & $\mathrm{RT}$ & & 300 & 500 \\
& $\boldsymbol{R a}(\boldsymbol{\mu m})$ & 2.919 & & 3.54 & 5.461 \\
\hline \hline \multirow{2}{*}{ Biaxial test } & $\mathrm{T}\left({ }^{\circ} \mathrm{C}\right)$ & $\mathrm{RT}$ & 100 & 200 & 300 \\
& $\operatorname{Ra}(\mu \mathrm{m})$ & 1.515 & 2.617 & 3.275 & 3.702 \\
\hline \hline
\end{tabular}




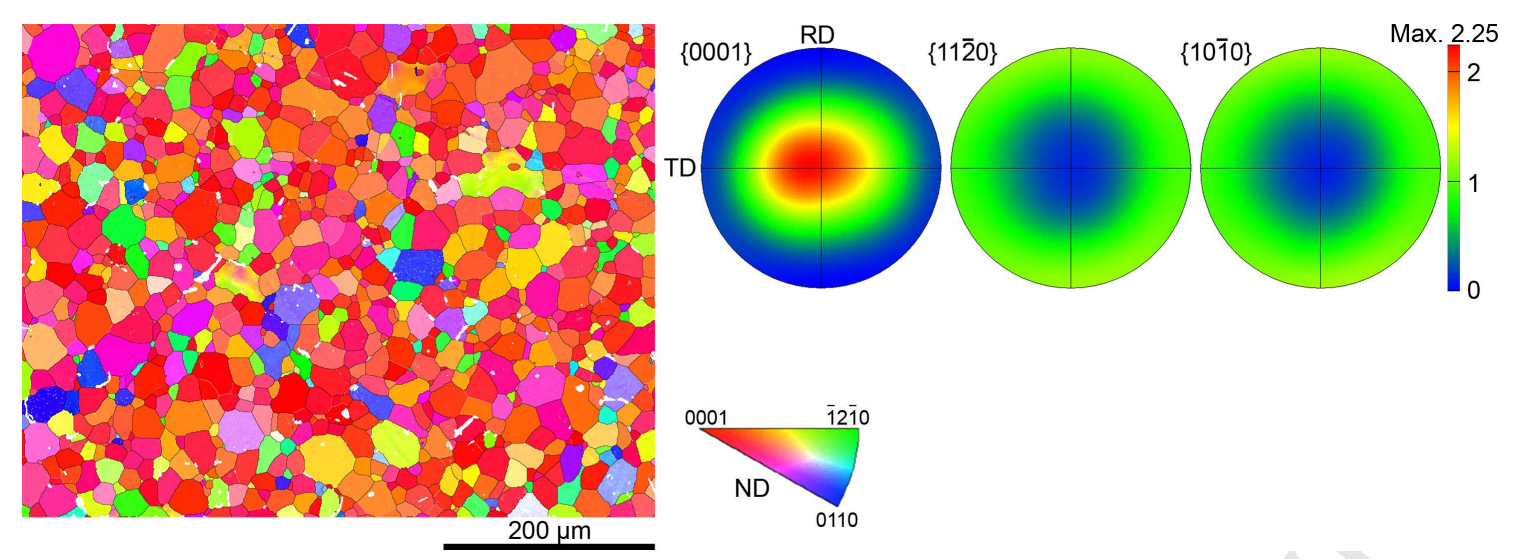




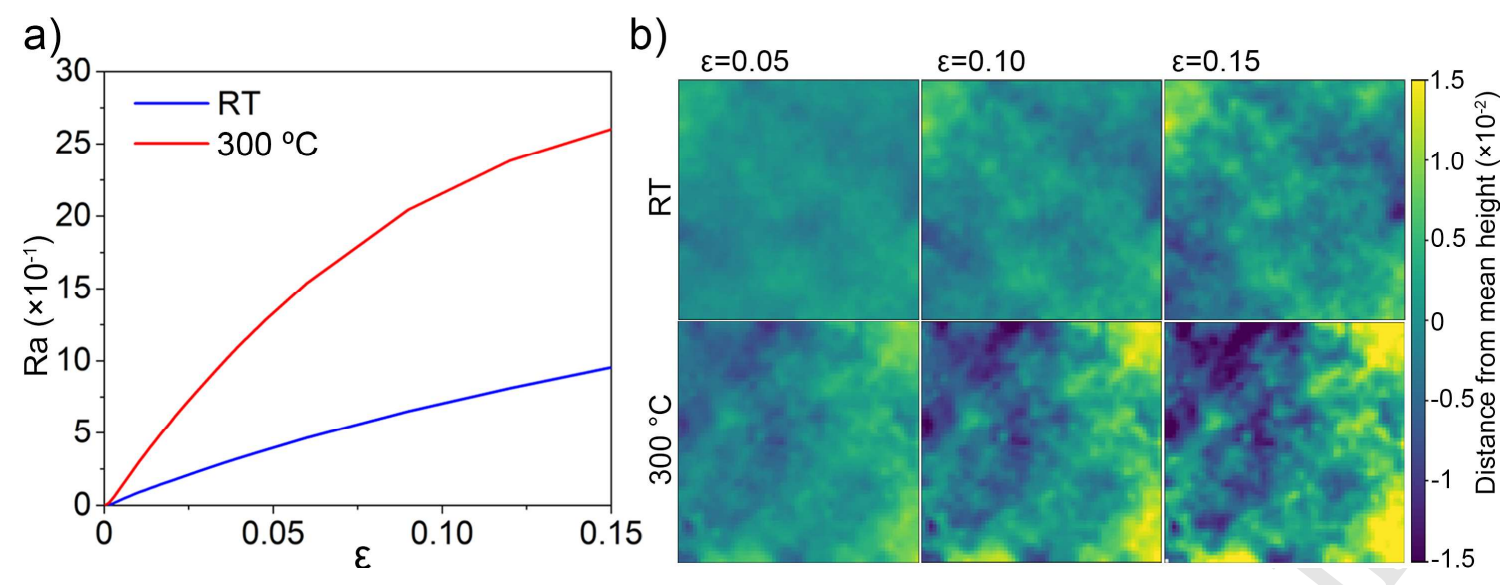


a)

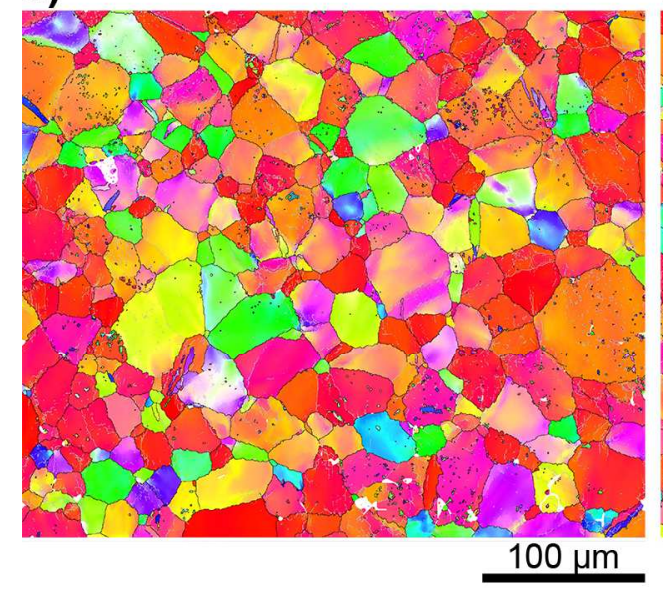

c)

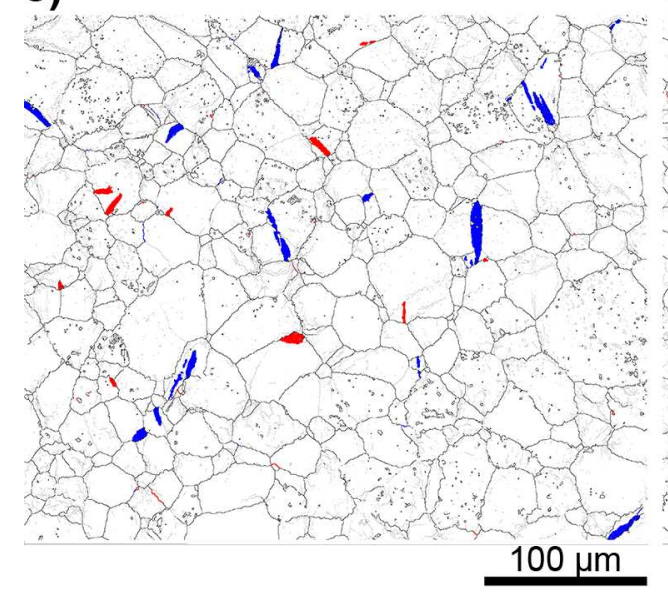

e)

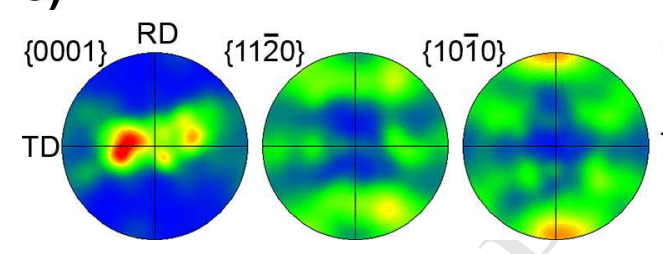

b)

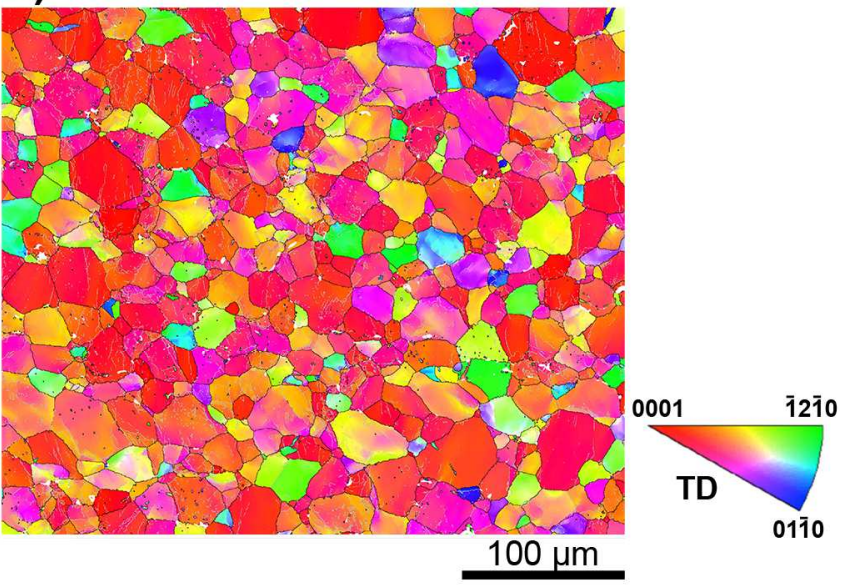

d)

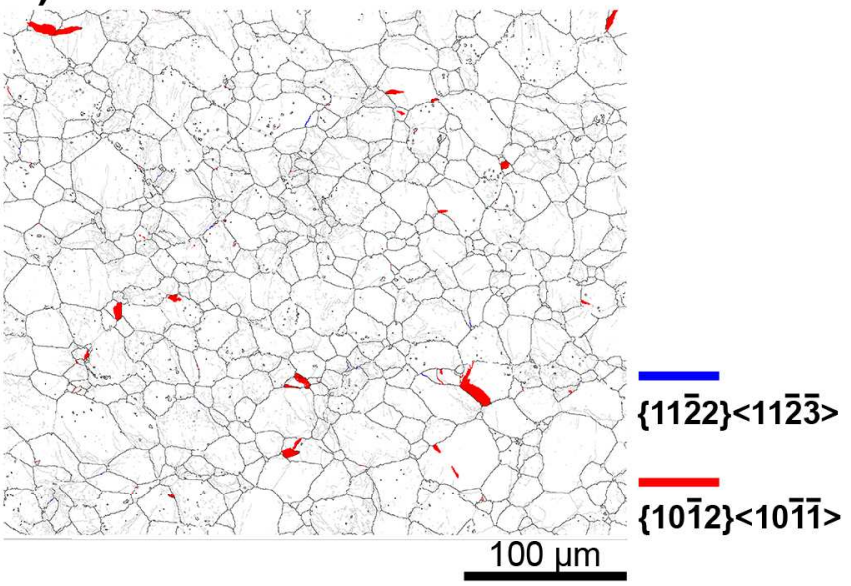

f)

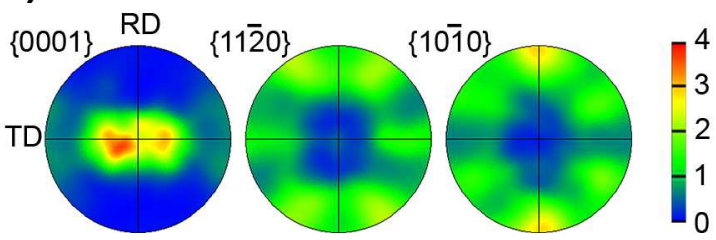


a)

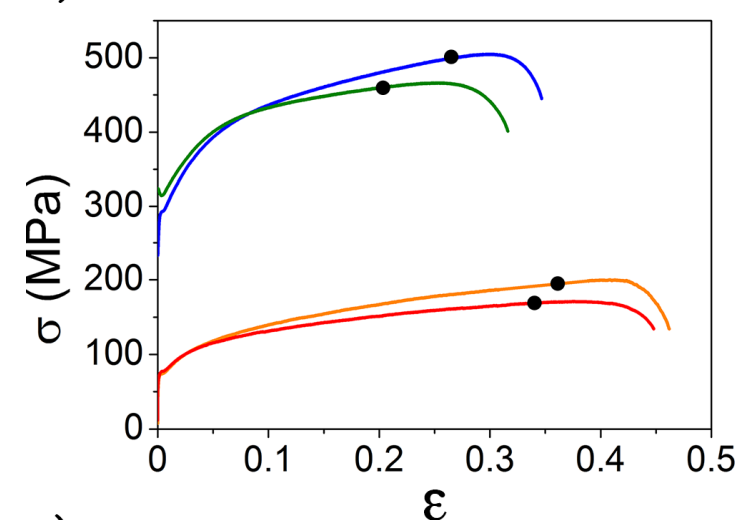

c)

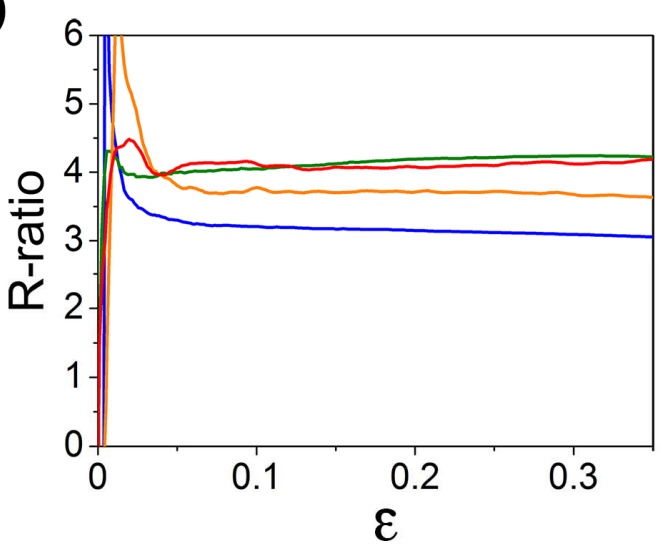

b)

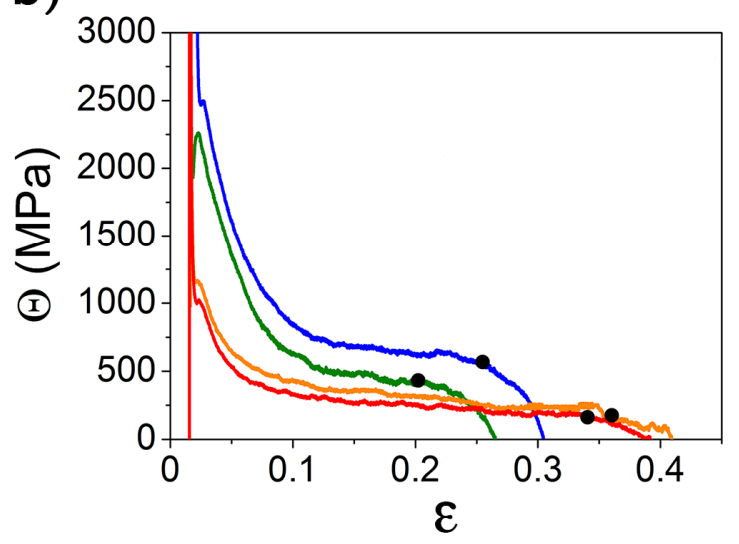

$$
\begin{aligned}
& \mathrm{RT}\left[\begin{array}{l}
-\mathrm{RD} \\
-\mathrm{TD}
\end{array}\right. \\
& 300^{\circ} \mathrm{C}\left[\begin{array}{l}
\mathrm{RD} \\
-\mathrm{TD}
\end{array}\right.
\end{aligned}
$$




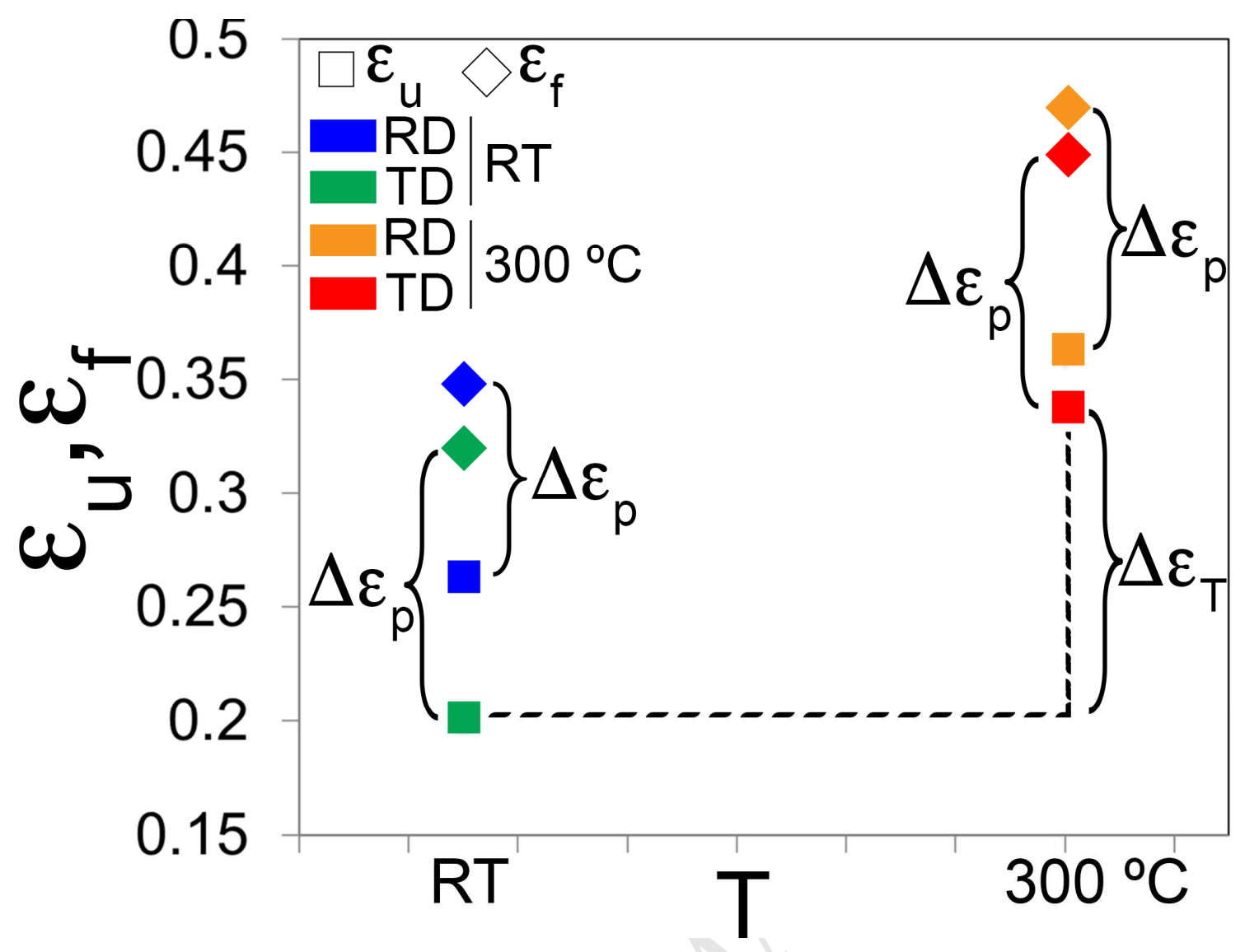




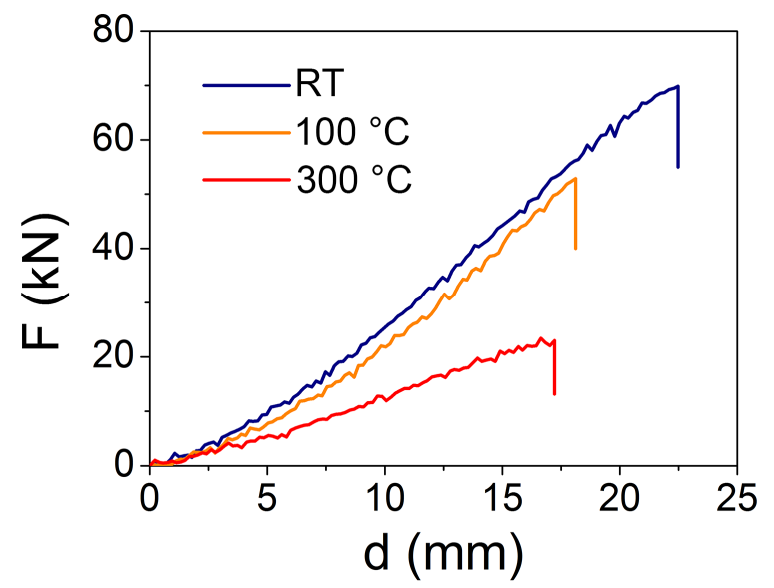




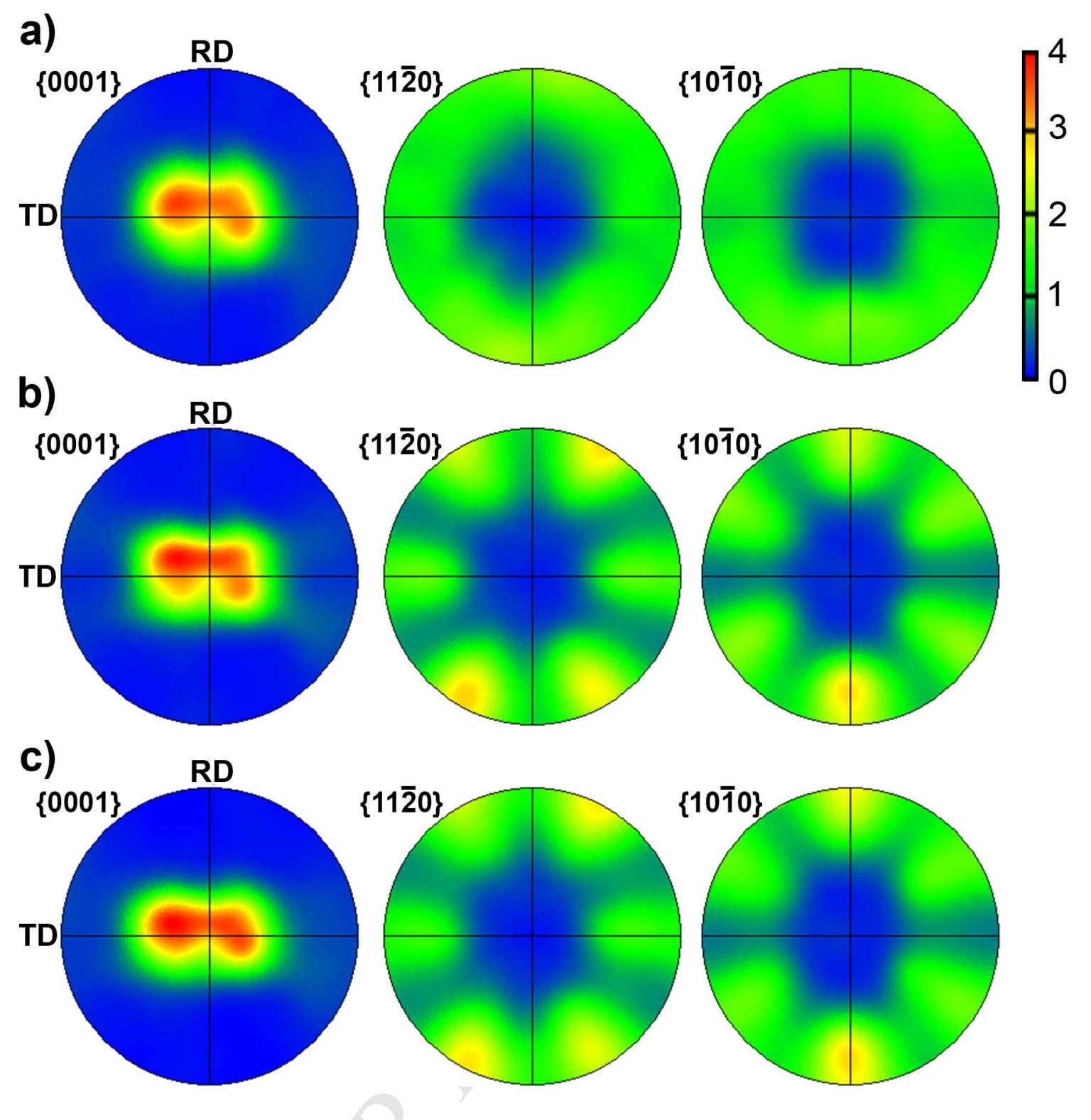




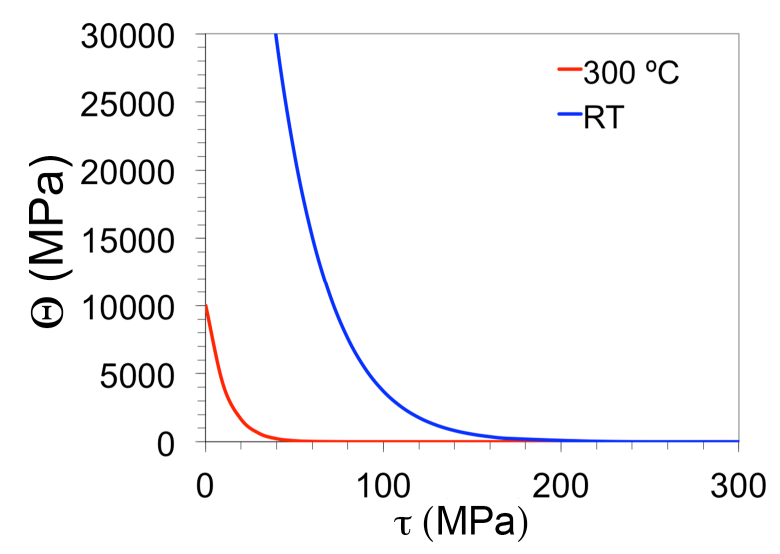



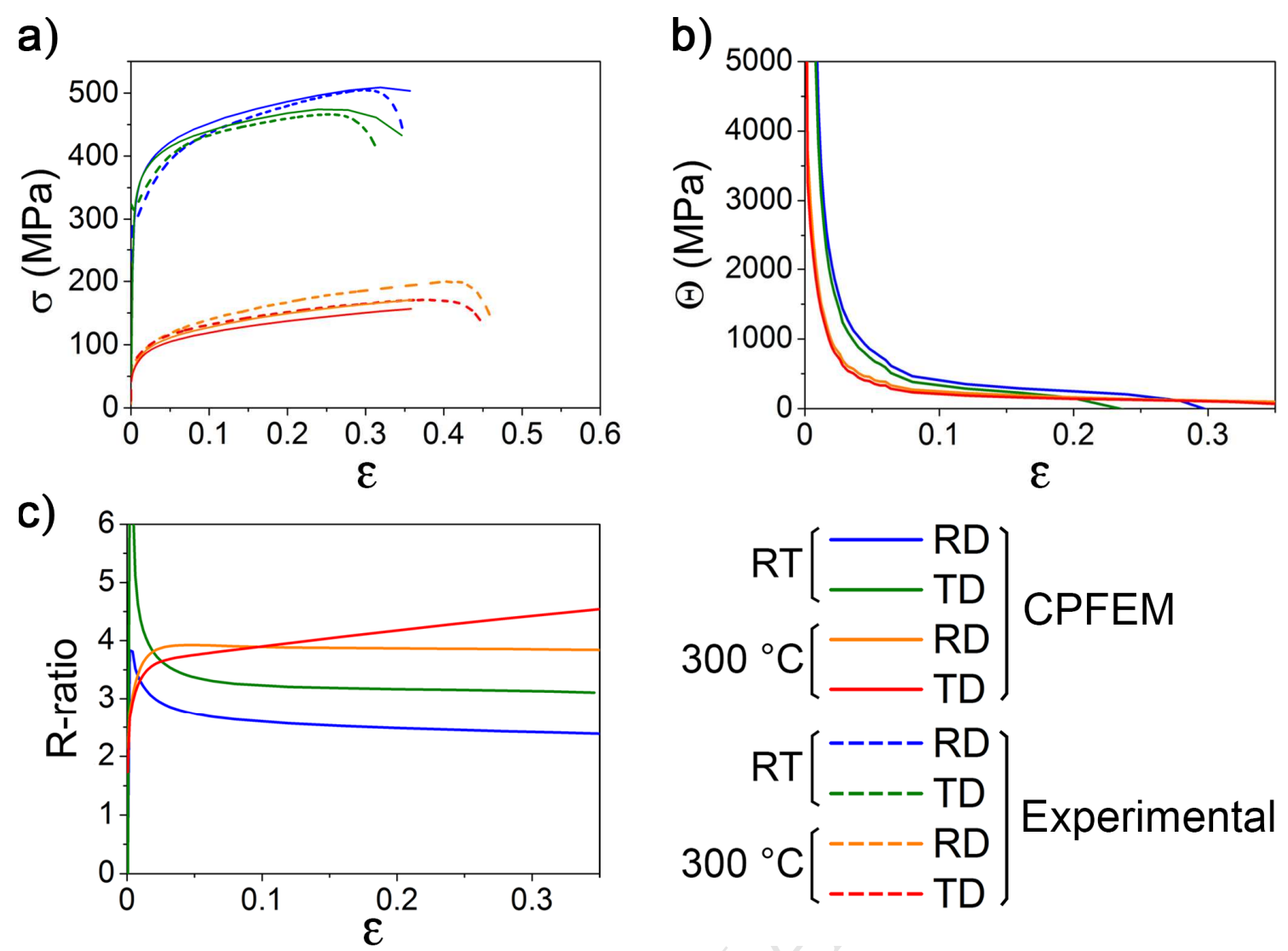
a)

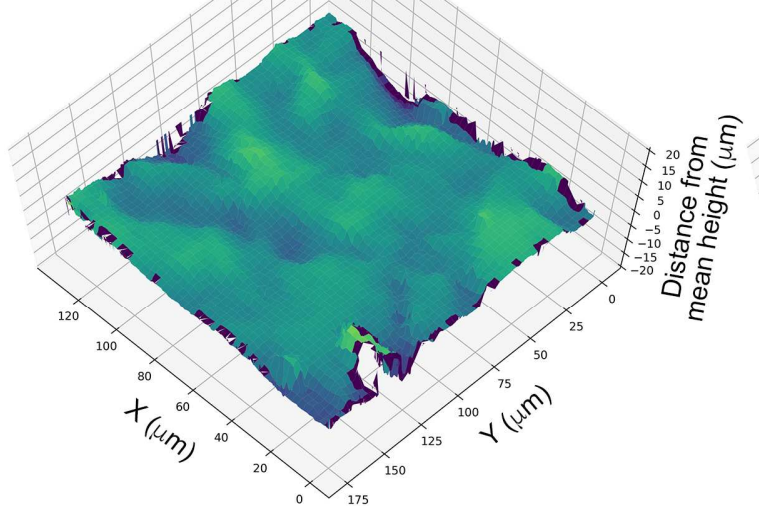

b)

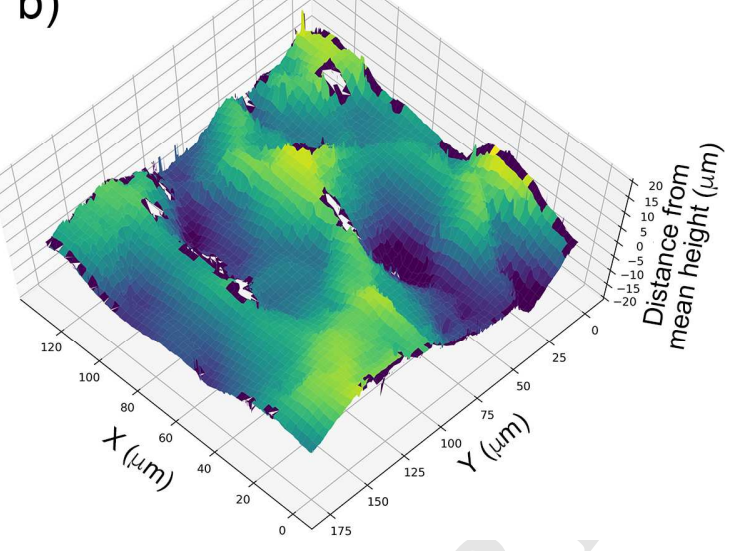

